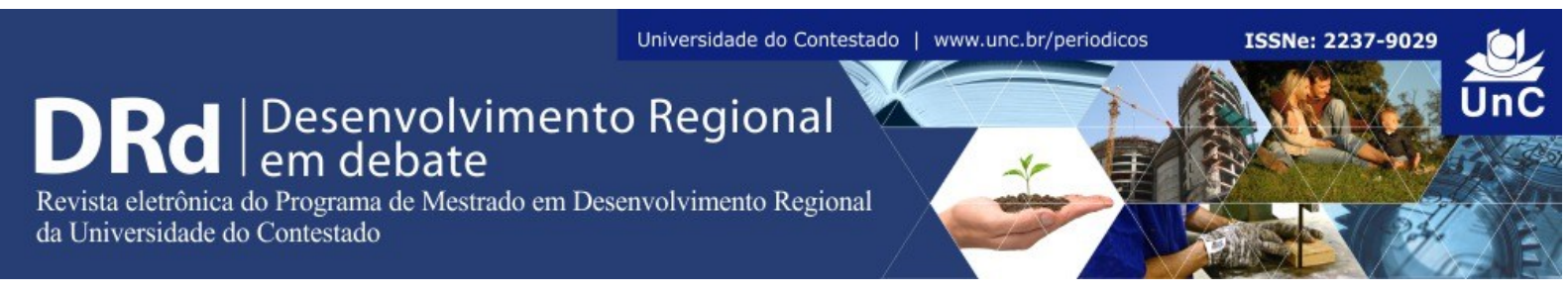

\title{
POSSIBILIDADES E DESAFIOS DO MANEJO DE FRAGMENTOS DE FLORESTA OMBRÓFILA MISTA COMO ALTERNATIVA DE DESENVOLVIMENTO NO PLANALTO NORTE CATARINENSE
}

\author{
Lauro William Petrentchuk ${ }^{1}$ \\ Franco Schinato ${ }^{2}$ \\ Jairo Marchesan ${ }^{3}$
}

\begin{abstract}
RESUMO
As condições ambientais e a cultura local são características associadas do território do Planalto Norte Catarinense (PNC). A utilização dos produtos da floresta são inerentes ao estilo de vida local. Entretanto, a alteração da paisagem rural, proporcionou mudanças nas relações das comunidades com o meio ambiente. Assim, o artigo trata do desenvolvimento regional sustentável no PNC, sob a ótica da floresta nativa como ferramenta motivadora. Este estudo busca expor as possibilidades do manejo da mesma com base em iniciativas que estão emergindo no cenário desenvolvimentista em relação a sustentabilidade. Metodologicamente, o trabalho se volta para revisões bibliográficas e estudos recentes da temática. A pesquisa se caracteriza como qualitativa, quanto ao objetivo principal de expor dados de investigação, e de natureza exploratória descritiva, com interesse em observar, descrever e correlacionar fatos ou fenômenos de uma determinada realidade. O trabalho apresenta evidências de oportunidades que podem ser destacadas como fatores para a conservação e uso racional dos fragmentos da floresta no PNC, além de possibilidades de alternativas de trabalho e renda. Dentre estas, se encontra o manejo florestal de Produtos Florestais Não Madeiráveis (PFNM), como o pinhão, frutos nativos, plantas medicinais e comestíveis e a possibilidade de utilização de sistemas de Pagamento por Serviços Ambientais (PSA). Desta forma, as análises, discussões e considerações apresentadas neste estudo, são oportunidades para o uso dos remanescentes nativos que podem ser planejados a médio e longo prazo, permitindo seus vários potenciais de uso e sustentabilidade no referido território.
\end{abstract}

Palavras Chave: Desenvolvimento Regional Sustentável. Floresta Ombrófila Mista. Mata de Araucária. Manejo Florestal. Pagamentos por Serviços Ambientais.

\footnotetext{
${ }^{1}$ Eng $^{\mathrm{o}}$. Florestal, Mestre em Desenvolvimento Regional, docente do Instituto Federal de Educação, Ciência e Tecnologia de Santa Catarina (IFSC). Santa Catarina. Brasil. E-mail: laurowilliam@yahoo.com.br

${ }^{2}$ Eng $^{\mathrm{o}}$. Florestal, discente do curso de Especialização em Desenvolvimento Rural Sustentável do Instituto Federal de Educação, Ciência e Tecnologia de Santa Catarina - IFSC. Santa Catarina. Brasil. E-mail: francoschinato@gmail.com

${ }^{3}$ Geógrafo, professor do Programa de Mestrado em Desenvolvimento Regional da Universidade do Contestado. Santa Catarina. Brasil. E-mail: jairo@unc.br
} 


\section{ABSTRACT \\ MANAGEMENT POSSIBILITIES AND CHALLENGES OF THE MIXED RAINFOREST FRAGMENTS AS ALTERNATIVE FOR THE DEVELOPMENT OF THE PLATEAU OF NORTHERN SANTA CATARINA}

Historically the environmental conditions and local culture are characteristics associated to the conjuncture of the north plateau de Santa Catarina (PNC). The use of forest products has inherent rise to the local lifestyle. However, the change to the countryside also provided changes in the relations of the communities with the environment. Thus, the article deals with sustainable regional development in the PNC on the central perspective of native forest as a motivating tool. This study seeks to expose the management of possibilities in the same building on initiatives that are emerging in the developmental stage in relation to sustainability. Methodologically, the work turns to literature reviews and recent studies on the subject. The research is characterized as qualitative, as the main purpose of exposing data research, and descriptive exploratory nature, with interest to observe, describe and correlate facts or phenomena of a certain reality occurred. The study shows that opportunities can be highlighted as factors for the conservation and rational use of existing fragments in the PNC, and turn into work and income alternatives. Among these, is the forest management NTFP (like pine nuts, native fruits, medicinal plants and edible) and payment systems environmental services (PSA) made possible in the region. Thus, analyzes, discussions and considerations presented in this study are a number of opportunities for the use of native remnants, which can be planned in the medium and long term, allowing their various potential uses and sustainability over time at PNC

Keywords: Sustainable Regional Development. Mixed Rain Forest. Araucaria Forest. Forest management. Payments for Environmental Services.

\section{INTRODUÇÃO}

As relações estabelecidas entre os seres humanos e o meio ambiente, são parte da história do desenvolvimento da sociedade. Historicamente, os processos de uso e exploração dos recursos naturais ocasionaram diferentes implicações sobre o ambiente, interferindo diretamente na relação da humanidade com a natureza.

Particularmente, o Brasil dispõe de um território com características ambientais privilegiadas, coberto por diferentes biomas, os quais, possuem formações florestais abundantes e elevada disponibilidade de recursos naturais.

O bioma Mata Atlântica apresenta especial relevância, pois, além de sua elevada diversidade biológica é exímio fornecedor de benefícios essenciais à manutenção da vida, como pode ser constatado no fato do bioma abrigar a maior parte da população brasileira.

Segundo o Ministério do Meio Ambiente (MMA, 2011), a Mata Atlântica é formada por um conjunto de formações florestais e ecossistemas associados, os quais, em sua extensão original, ocupavam cerca de 130 milhões de hectares, e atualmente, em fragmentos acima de 100 hectares, existem apenas 7,3\% de sua cobertura original. 
O território do Planalto Norte Catarinense (PNC) está inserido dentro da área de abrangência do bioma Mata Atlântica, abrigando na totalidade de sua extensão, uma de suas formações florestais mais características, a Floresta Ombrófila Mista (FOM), nomeada, também, como Mata de Araucárias. Esta formação apresenta espécies e fitofisionomia peculiar, com dossel predominado pela espécie Araucaria angustifolia, considerada seu símbolo. A intensa exploração a qual esta formação florestal foi submetida é relatada por Salvador e Da-Ré (2002), ao afirmarem que a principal causa da degradação desta floresta no sul do Brasil tem sua origem na extração madeireira do pinheiro, que ficou inviabilizada em menos de 80 anos de exploração irracional.

O manejo desordenado da floresta no referido território do PNC ao longo dos últimos séculos, apresenta reflexos na relação entre a FOM e a população local. Este processo histórico ocasionou implicações no modo de vida do meio rural, tendo alterado também suas características socioeconômicas. Estas situações sugerem a demanda por desenvolvimento sustentável que, ambientalmente, está conectado à existência, manutenção e uso sustentável dos remanescentes florestais nativos, servindo como estímulo à conservação e preservação ambiental.

Ações de sustentabilidade, conservação e a conscientização ambiental no uso dos recursos florestais são crescentes no PNC, sobretudo por meio da evolução das políticas públicas nos temas referidos. Atualmente, diferentes ações já foram viabilizadas na perspectiva da sustentabilidade. Nesta listagem podem ser elencados os Produtos Florestais Não Madeiráveis (PFNM), como a erva-mate em sistemas de adensamentos de florestas, a coleta do pinhão e os sistemas de Pagamentos por Serviços Ambientais (PSA) desenvolvidos no PNC. Ainda que estas tenham sido as principais ações concretizadas, há, ao final deste estudo, abordagens sobre outros potenciais de uso das florestas nativas, como mecanismos para a promoção do desenvolvimento rural sustentável.

Esta pesquisa se caracterizada por sua natureza exploratória descritiva, com objetivo de proporcionar familiaridade ao tema de estudo (GIL, 2008), por meio de revisões bibliográficas de estudos no território, compilação de dados secundários sobre a temática, e por tratar das características da população do PNC e sua relação com a floresta nativa.

A pesquisa está dividida em duas partes. Inicialmente, são apresentadas abordagens sobre o tema do desenvolvimento sustentável e os fatores inerentes à sua natureza em conjunto com a contextualização das características ambientais verificadas historicamente no território do PNC. Em uma segunda etapa, são apresentadas possibilidades de manejo de usos múltiplos da floresta nativa como mecanismo promotor de tal desenvolvimento.

Por fim, foram realizadas considerações como forma de conectar os diferentes fatores inerentes aos processos propostos, de modo a aprofundar as discussões sobre o tema.

Desta maneira, este estudo busca evidenciar, com base em ações já viabilizadas, oportunidades para a conservação e uso racional dos fragmentos florestais existentes no Planalto Norte Catarinense, as quais podem ser transformadas em alternativas de trabalho e renda. As análises desenvolvidas são perspectivas de uso dos remanescentes nativos, de modo planejado no médio e longo prazo, de maneira a permitir que seus vários potenciais de uso se sustentem no PNC. 


\section{CONSIDERAÇÕES SOBRE DESENVOLVIMENTO E SUSTENTABILIDADE}

No senso comum, desenvolvimento é sinônimo de crescimento econômico. No entanto, o crescimento econômico pode ser entendido como um dos fatores que levam ao desenvolvimento. Pode-se entender, também, que o crescimento econômico é uma das variáveis das atividades produtivas com as quais o desenvolvimento irá se caracterizar na economia moderna. A diferenciação entre crescimento econômico e desenvolvimento só ocorreu quando o Programa das Nações Unidas para o Desenvolvimento (PNUD) publicou o primeiro Relatório do Desenvolvimento Humano com o IDH (Índice de Desenvolvimento Humano) em 1990. Sobre o relatório, Veiga (2005, p. 07), diz que: “[...] nada pode ser mais didático quando é necessário explicar que crescimento só engendra desenvolvimento se seus frutos prolongarem a vida e melhorarem o nível educacional das populações desfavorecidas (pelo menos)".

O desenvolvimento não envolve apenas crescimento da economia ou apenas uma variação na produtividade, envolve mudanças de ordens qualitativas no modo de vida de toda uma sociedade. $\mathrm{O}$ desenvolvimento está condicionado à dinâmica de se considerar além do fator econômico, os fatores que podem propiciar melhores condições de vida em seus aspectos sociais, culturais e ambientais.

O termo desenvolvimento é polissêmico. No modelo econômico liberal, a economia é tida como capaz de gerar desenvolvimento com pouca interferência do Estado na economia, agindo apenas como regulador. Contudo, este posicionamento não se aplica a todos os setores da economia. É importante que exista a ação do Estado em diferentes intensidades para ajustar setores da economia. Esse papel coordenador do Estado remete-nos inelutavelmente para o papel das formas de organização da sociedade civil no processo de geração, distribuição e apropriação do conhecimento e das inovações dele advindas (MACIEL, 1996).

Neste sentido, para que a floresta natural que cobre o PNC possa contribuir com o desenvolvimento, é necessária a intervenção do Estado na formulação de políticas públicas que favoreçam atividades de usos múltiplos e sustentáveis dos remanescentes florestais nativos para um município, por exemplo. Para Cazella (2010, p. 135): “[...] entende-se, que as parcerias entre organizações da sociedade civil e setores públicos e privados tornam-se imprescindíveis no sentindo de construir uma base de serviços estratégicos de desenvolvimento $[\ldots]$ ".

Em se tratando de política pública, esta é diferente de política governamental. A primeira é um desejo da população e pode ser realizada por toda sociedade. Já, a segunda, é realizada apenas com a estrutura governamental, principalmente a sua administração. Para Heidemann e Salm (2010, p. 28): "Em seu conjunto, essas decisões e ações de governo e de outros atores sociais constituem o que se conhece com o nome genérico de políticas públicas". Da mesma forma que se identifica o desenvolvimento regional como uma política pública, esta não é autônoma e excludente das interferências do mercado e do capital mundial. Neste caso, não se deve falar em desenvolvimento regional desconsiderando a esfera política no aspecto econômico da globalização, sob pena do desenvolvimento não conseguir se manter como política pública em relação ao aspecto operacional do desenvolvimento regional. Sobre isso, Diniz (2009, p. 198) descreve: 
Do ponto de vista operacional, pensar uma política nacional de desenvolvimento regional implica pensar em uma nova regionalização do país para efeitos de política pública, em geral, a da política regional, em particular. [...] uma nova regionalização deveria considerar três critérios complementares e articulados: econômico, ambiental e político. O critério econômico deve ter como referência básica os efeitos de polarização exercidos pelas cidades, a partir de cuja hierarquia se definiriam as escalas de polarização, das centralidades e suas áreas complementares. $\mathrm{O}$ critério ambiental deveria buscar o ajuste dos recortes territoriais às necessidades de aproveitamento econômico do patrimônio natural e da sustentabilidade ambiental. Por fim, o critério de representação política deveria preservar a relação entre o recorte territorial e a identidade cultural e política de seus habitantes e suas instituições e, ao mesmo tempo, os aspectos de geopolítica e soberania nacional.

$\mathrm{Na}$ busca de melhorias para o desenvolvimento regional, a discussão maior a ser caracterizada por este estudo está na dimensão ambiental, tornando-a como um critério primordial para a busca do aproveitamento do patrimônio natural. Neste caso, são de fundamental importância os fragmentos florestais nativos e os seus manejos, respeitando-se os preceitos da sustentabilidade. A potencialização dos recursos naturais seria uma ferramenta de mudança, pois se consideraria as melhorias econômicas, sociais e ambientais para o PNC.

O uso dos remanescentes florestais nativos por meio do manejo sustentável têm como base a utilização de ativos territoriais naturais, aproximando o aspecto de potencialização dos capitais e recursos para que possam ser considerados no processo de desenvolvimento. Destacam-se os ativos naturais, que neste trabalho são as espécies florestais nativas como fatores endógenos para o desenvolvimento. Reafirmando este posicionamento, Borba (2011, p. 65) afirma que:

Esta característica central do desenvolvimento econômico baseado regionalmente [...] demonstra o potencial local de recursos humanos, institucionais e físicos, procurando-se reforçar o conceito mais amplo de desenvolvimento sustentável, onde se destaca o imperativo do planejamento das relações entre os homens e a natureza, determinado pelas necessidades ambientais e econômicas das futuras gerações.

A concepção de desenvolvimento endógeno, por exemplo, utiliza os recursos oriundos de uma dada região, sejam estes naturais ou culturais. Neste caso, a Floresta Ombrófila Mista pode ser uma das possibilidades às comunidades locais satisfazerem as necessidades humanas regionais.

O desenvolvimento resulta do compromisso da sociedade local e de mudanças básicas em seus costumes e condutas, o que admite substituir a concepção tradicional de "espaço" como simples cenário físico, por um contexto social de cooperação ativa, um "território" (ALMEIDA, 2005).

Quando se pensa na conservação das florestas nativas, deve-se refletir sobre a dinamização que este recurso oferece ao território. Assim, o desenvolvimento promove mudanças estruturais na sociedade frente ao meio ambiente florestal que compõe a região, juntamente com suas especificidades materiais e imateriais.

Aqui, assume-se a concepção de desenvolvimento defendida em Dallabrida (2011, p. 19): 
O desenvolvimento (local, regional, territorial) pode ser entendido como um processo de mudança estrutural empreendido por uma sociedade organizada territorialmente, sustentado na potencialização dos recursos e ativos (materiais e imateriais, genéricos e específicos) existentes no local, com vistas à dinamização econômica e a melhoria da qualidade de vida de sua população.

Esta concepção vem ao encontro da proposta do estudo, em que os ativos dos fragmentos da FOM podem servir de recursos potencializadores de desenvolvimento local, regional ou territorial. Por meio destes recursos florestais e serviços prestados pelas florestas, poderá haver dinamização econômica e consequentemente social e ambiental.

O entendimento que se pode ter das abordagens aqui descritas é de que, para haver desenvolvimento, as bases culturais, ambientais, sociais, econômicas e políticas, devem permanecer em conformidade para que possam auxiliar na promoção da equidade e justiça social, ambiental e humana. Esta questão remete ao debate sobre a sustentabilidade do desenvolvimento.

De maneira geral, o desenvolvimento sustentável leva em consideração as dimensões econômica, social e ambiental. A Comissão Mundial Sobre Meio Ambiente e Desenvolvimento (CMDMA, 1998), define que o desenvolvimento sustentável é o de satisfazer as necessidades do presente sem comprometer a capacidade das futuras gerações de satisfazerem suas próprias necessidades.

Chiaravalloti e Pádua (2011, p. 25), explicam que: “[...] segundo os adeptos dessa ideia, a palavra "desenvolvimento" refere-se a algo que necessita de aumento de consumo e do uso dos recursos, enquanto "sustentável" refere-se a um estado sem aumento do uso de recursos".

Ainda, para Chiaravalloti e Padua (2011, p. 25),

O desenvolvimento sustentável apenas se refere a um modo mais pragmático e coletivo para as soluções sustentáveis e leva em conta que o avanço tecnológico e a maior eficácia na produção são as variáveis principais. As críticas se baseiam no fato de que as políticas sustentáveis devem ir além de mudanças tecnológicas e fundamentar-se em mudanças [...] da relação do homem com a natureza.

Raud (1999, p. 170), lembra que: “[...] a estratégia de desenvolvimento sustentável, deve supor uma melhor coordenação de esforços públicos, privados e comunitários".

O conceito de desenvolvimento sustentável tem muita relação com o conceito de ecodesenvolvimento, o qual ganhou notoriedade a partir da conferência de Estocolmo na década de 1970 e também de Ignacy Sachs (1986), que apresentaram princípios para o desenvolvimento como: a) satisfazer as necessidades humanas básicas; b) tornar-se solidários para com as gerações futuras, c) preservar o meio ambiente, d) garantir a participação popular, e) garantir estrutura social de apoio ao emprego e à renda.

Para Cazella (2008, p. 10):

Na atualidade, não é o fim do desenvolvimento que figura nas manchetes, mas a noção do desenvolvimento sustentável. A difusão desse novo estilo de desenvolvimento está associada à publicação em 1988 do relatório Brundtland que deu $[. .$.$] um novo fôlego ao pensamento do desenvolvimento.$ 
O desenvolvimento sustentável trata diretamente de uma nova forma da população se relacionar com o ambiente, garantindo a sua própria continuidade e a de seu meio externo. Para compreender tal vinculação, é preciso, segundo Veiga (2010), integrar o crescimento econômico com a conservação dos recursos naturais tendo contato com três conhecimentos fundamentais, tais sejam: (a) os comportamentos humanos, econômicos e sociais, que são objetos da teoria econômica e das demais ciências sociais; (b) a evolução da natureza, que é objeto das ciências biológicas, físicas e químicas; (c) a configuração social do território, que é objeto da geografia humana, das ciências sociais e da organização do espaço.

Buarque (2006, p. 25), lembra que para ser considerado sustentável, o desenvolvimento deve:

[...] mobilizar e explorar as potencialidades locais e contribuir para elevar as oportunidades sociais e a viabilidade e competitividade da economia local; ao mesmo tempo, deve assegurar a conservação dos recursos naturais locais, que são a base das suas potencialidades e condição para a qualidade de vida da população local.

O desenvolvimento é apresentado por Sachs (2008, p. $15-16$,) como um equilíbrio de sintonia fina entre cinco dimensões:

[...] (a) a social, fundamental por motivos tanto intrínsecos quanto instrumentais, por causa da perspectiva de disrupção social que paira na forma ameaçadora sobre muitos lugares problemáticos do nosso planeta; (b) a ambiental, com as suas duas dimensões (os sistemas de sustentação da vida como provedores de recursos e como "recipientes" para a disposição de resíduos); (c) a territorial, relacionado à distribuição espacial dos recursos, das populações e das atividades; (d) a econômica, sendo a viabilidade econômica a conditio sinequa non para que as coisas aconteçam; (e) a política, pois a governança democrática é um valor fundador e um instrumento necessário para fazer as coisas acontecerem; a liberdade faz toda a diferença.

Buscar o avanço em direção à sustentabilidade é uma escolha da sociedade. No entanto, o atual modelo econômico é nocivo ao meio ambiente. Estas escolhas só serão possíveis com o melhor uso dos recursos e envolvimento significativo da sociedade. Assim, o modelo de desenvolvimento sustentável obriga a sociedade a pensar em questões a longo prazo, valorizar o seu espaço e perceber que a situação atual das atividades sociais da população global está ameaçando gravemente a perspectiva de vida das gerações atuais e futuras.

Uma alternativa que ainda é recente e necessita de maior compreensão é a necessidade de preservação e reconstrução das paisagens locais.

Conforme Dallabrida (2012, p. 42):

Atualmente há uma visível tendência pela preservação, ou reconstrução da identidade dos territórios, apesar do intenso processo de globalização. Esta situação desafia alguns lugares a buscar potencializar seus recursos naturais, sociais e culturais como ativos para estratégias de desenvolvimento sustentável.

Com relação à identidade territorial, o desenvolvimento sustentável está vinculado aos ativos da região, que neste caso são os produtos e serviços provenientes dos fragmentos florestais. Para Pollice (2010, p. 17): 


\begin{abstract}
A ativação destes recursos não deve ser preordenada a obtenção e objetivos meramente econômicos [...] mas a uma finalidade mais ampla de desenvolvimento que pode coincidir com a plena realização de potencialidades do lugar. [...] a preservação dos valores identitários é condição iniludível para a situação de valor do território, e requer a manutenção do equilíbrio social, político e ambiental sobre os quais o sentimento identitário da comunidade local se funda.
\end{abstract}

Os autores argumentam a necessidade de considerar que as soluções políticas nem sempre são benéficas e são deixadas sempre no campo da política. Já, as propostas de soluções acadêmicas instigam e apresentam resultados sobre situações atuais dos diferentes sistemas. Entretanto, as soluções mais imediatas e de grande relevância são muitas vezes enfraquecidas e desvalorizadas. No caso das florestas nativas, a solução para garantir sua longevidade, manutenção e conservação de recursos naturais, grande parte ocorre através do manejo sustentável. Obviamente que, somente este quesito não é suficiente. Pesquisas, ações com populações locais, interação sociedade e natureza, valorização dos recursos como água, solo, atmosfera, fazem parte deste processo que muitas vezes é frágil na concepção e não é realizado pelo poder público ou privado, nem com a sociedade civil. Ou seja, não se tornam políticas públicas básicas para o desenvolvimento sustentável. Finalmente, Miller e Spoolman (2012, p. 11), ressaltam: "[...] em qualquer caso, uma mudança da sociedade rumo ao desenvolvimento sustentável depende, em última instância, das ações dos indivíduos, começando com as escolhas diárias que todos nós fazemos".

Portanto, além das várias esferas que o desenvolvimento sustentável abraça, o desenvolvimento sustentável ainda está na responsabilidade de cada indivíduo sobre a sua ação, sendo esta econômica, social ou ambiental. As ações devem ser responsáveis e coerentes com a realidade do lugar. Fatores locais podem auxiliar e muito na questão do desenvolvimento sustentável. Cabe superar os obstáculos ainda sólidos por falta de políticas públicas e ter uma visão sistêmica do território, da paisagem e das potencialidades identitárias.

\title{
A PAISAGEM DO PNC
}

A região do Planalto Norte Catarinense (PNC) foi palco de exuberantes Matas de Araucária, em estágio de sucessão avançada e elevado número de indivíduos clímax por área.

\begin{abstract}
A presença da Araucária ou Pinheiro (Araucaria angustifolia), com seu tronco reto e sua copa característica, sobressaindo acima da altura média da floresta, imprime uma fisionomia inconfundível a esse tipo florestal. Além dessa, espécies como Imbuia (Ocotea porosa), a Canela Lageana (Ocotea pulchella), a Erva Mate (Ilex paraguariensis), o Butiá (Butia eriospatha), a Bracatinga (Mimosa scabrella), o Xaxim (Dicksonia sellowiana) e tantas outras contribuem para caracterização desse ecossistema (CASTELLA; BRITEZ, 2004, p. 07).
\end{abstract}

Segundo a classificação proposta por Klein (1978), e adaptada por Vibrans et al. (2013), no estado de Santa Catarina, a Floresta Ombrófila Mista (FOM) cobria uma área de $42.851 \mathrm{~km}^{2}$, representando $45 \%$ da área total do estado, enquanto a Floresta Ombrófila Densa $31 \%$, a Floresta Estacional Decidual 8\%, os Campos Naturais 14\% e demais regiões 2\%.

A fitogeografia do estado de Santa Catarina apresenta distintos ecossistemas, ainda que dentro do bioma Mata Atlântica. Estes possuem em comum, um regime de chuvas bem

DRd - Desenvolvimento Regional em debate (ISSNe 2237-9029) 
distribuídas ao longo do ano, e elevada disponibilidade de recursos hídricos. Assim, cada um destes ecossistemas possui características locais específicas e diversas, nas diferentes ofertas e usos de produtos e serviços ecossistêmicos. Há alterações na relação com a floresta ao longo do estado, ainda que em todas regiões há evidências de sua intensiva exploração. A FOM possui elevada área de abrangência e assim se tornou, historicamente, referência ambiental, socioeconômica e cultural para diferentes territórios, sobretudo a do PNC.

A princípio o território do PNC era até a chegada da Companhia Colonizadora Lumber no início do século XX, um território praticamente explorado pelas comunidades tradicionais, entre eles, os caboclos, que mantinham atividades econômicas extensivas, como a criação de gado bovino, a extração da erva-mate, pequenos cultivos agrícolas, alguns engenhos de serrar madeira e beneficiar erva-mate, a caça de animais selvagens e a coleta de frutos silvestres (THOMÉ, 1995).

\begin{abstract}
A história de ocupação humana na região é na verdade bem mais antiga, como devem ter percebido logo os norte-americanos que vieram trabalhar na empresa e se estabelecer ali. Após séculos de presença de povos indígenas na região, tropeiros começaram a se estabelecer a partir do início do século XIX, principalmente mais próximos a Rio Negro e nos campos de São João (atual Matos Costa), onde era mais propícia a criação de gado. Desde o século XVIII, a rota dos tropeiros que partia do Rio Grande do Sul passava pela região de Rio Negro, a cerca de $50 \mathrm{~km}$ da futura cidade de Três Barras, para atingir a feira de Sorocaba, com o intuito de comercializar animais (MACHADO, 2004, p. 60).
\end{abstract}

O ciclo de exploração intensiva da FOM no PNC, está intimamente relacionada com o advento do ciclo da madeira iniciado pela empresa Lumber, em 1909, na região de Três Barras. De acordo com Thomé (1983), dos três mil quilômetros quadrados adquiridos pela empresa no Planalto Norte, pelo menos quatro milhões de araucárias e dois milhões de imbuias e cedros foram cortados em menos de 30 anos. O autor Tres et al. (2011) relata que a chegada da colonização ocorreu sob incentivos governamentais brasileiros, que permitiam à companhia a construção de estradas de ferro e autorização para explorar a madeira da zona de até $15 \mathrm{~km}$ de cada lado do eixo da linha principal, visando fornecimento de tabuas e dormentes para os trilhos, o que, posteriormente, se tornou um enorme estoque de pinheiros e imbuias para exportação. De acordo com Marques (2007), a atividade da companhia ferroviária, durou até 1940, quando o governo incorporou a empresa e parte de suas terras, ainda que o ápice da exploração tenha ocorrido entre os anos de 1950 e 1970, quando a madeira da araucária esteve entre os principais itens das listas de exportações brasileiras (GUERRA et al. 2002).

Este cenário contribuiu para uma grave fragmentação deste ecossistema. Dos cerca de 200 mil km² originalmente ocupados por esta formação florestal, restam aproximadamente $2 \%$, que perfazem $4.000 \mathrm{~km}^{2}$, distribuídos em fragmentos dispersos (MEDEIROS, 2002; GUERRA et al. 2002; PROCHNOW, 2009, Apud ALARCON et al. 2011, p. 27).

A seguir, a Figura 5, apresenta uma perspectiva da cobertura de remanescentes da FOM, no estado de Santa Catarina.

Com a redução das áreas florestais na região do $\mathrm{PNC}$, ocorreram alterações na paisagem rural e, de acordo com Petrentchuk (2015), após o término do ciclo da madeira, o meio rural se voltou às atividades agrícolas, com predomínio das monoculturas de fumo, milho, soja, feijão, batata, pinus, eucalipto, dentre outros. Isso isolou os fragmentos florestais 
nativos das áreas produtivas, o que contribui para desintegração do homem à floresta, dificultando a possibilidade de manejo sustentável ou de usos múltiplos da mesma.

Embora a realidade ambiental deste território tenha sido comprometida em função do histórico de gestão florestal desordenada, não se pode dizer que o PNC tenha perdido a ligação com a floresta e seus produtos e serviços. Segundo Marques et al. (2012), há uma relação histórica da utilização de recursos florestais como a erva-mate, na forma de chimarrão e chá, e do pinhão, por parte dos indígenas, habitantes da região mesmo antes da chegada dos espanhóis e portugueses. O contínuo uso destes recursos vem sendo mantido ao longo dos anos e as tradições e culturas locais valorizadas pela população, constituem uma característica viva nos hábitos atuais dos indígenas e caboclos.

Figura 5 - Localização dos remanescentes florestais da FOM em SC

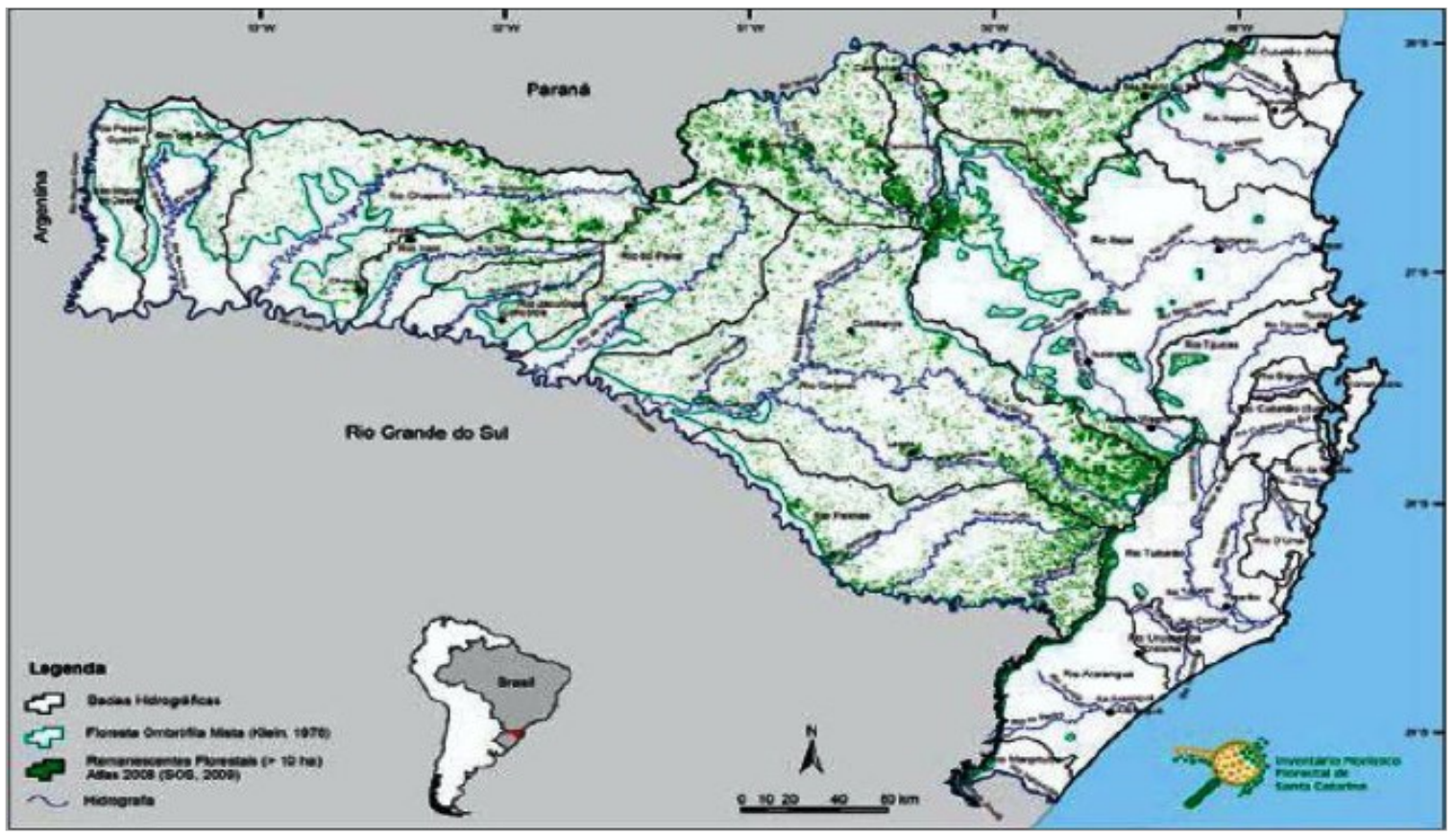

Fonte: Vibrans et al. (2013) adaptado de: SOS Mata Atlântica (2009)

\section{A FLORESTA COMO INSTRUMENTO LEGAL DE DESENVOLVIMENTO SUSTENTÁVEL NO PNC}

Para a adoção de políticas de gestão sustentável dos ecossistemas deve-se considerar o conhecimento humano sobre a dinâmica ecológica, compreendendo as complexidades que envolvem os ecossistemas (BENNET, 2005).

Dadas às características ambientais da região do $\mathrm{PNC}$, onde a $\mathrm{FOM}$ abrange praticamente a totalidade de sua área, há um ambiente com produtos e benefícios de uso tradicional pelas diferentes comunidades da sua sociedade. O consumo da erva-mate e do pinhão são tão naturais nos hábitos locais que estes passaram a ser, naturalmente, uma cultura social. Sugere-se a introdução de trabalhar com dinâmicas associadas a métodos de manejo sustentável e valorização de alguns produtos provenientes dos fragmentos florestais. Alguns 
deles podem ser úteis ao desenvolvimento regional como ferramentas de dinamização do território.

\section{ALTERNATIVAS DE DESENVOLVIMENTO: PRODUTOS FLORESTAIS NÃO MADEIRÁVEIS (PFNM)}

Estes produtos estão presentes em todas as formações florestais. Porém, devido à sua característica podem se tornar culturas locais importantes para as comunidades tradicionais. Os PFNM são aproveitados sob regimes de menor impacto ambiental quando comparado ao aproveitamento direto da madeira. Seus usos estão previstos nos Art. $21^{\circ}$ e $22^{\circ}$, da Lei $\mathrm{n}^{\mathrm{o}} 12.561 / 12$, do Novo Código Florestal Brasileiro.

Os PFNM compõem uma extensa lista de produtos, que, de um modo geral, estão relacionados ao aproveitamento de plantas comestíveis e medicinais, frutas, castanhas, fibras, óleos essenciais, resinas, látex, dentre outros (GUERRA, 2008).

Mesmo com a alteração na paisagem rural do PNC, a FOM ainda apresenta estreita relação com as comunidades locais, pois, naturalmente está presente na forma de fragmentos na maioria das propriedades rurais da região. A sua manutenção e conservação está relacionada com a existência de Unidades de Conservação (UC) e com a adoção de regimes de manejo sustentável dos fragmentos nativos ao longo do território. No caso dos PFNM para o PNC, os remanescentes florestais dispõem de diversos recursos com possibilidades de uso sustentável. No entanto, a maioria de seus produtos ainda carece de subsídios, estudos e políticas públicas, como suporte à viabilização dos usos.

Dentre vários PFNM, a erva-mate foi a alavanca de desenvolvimento de muitos municípios no PNC. A exploração da erva-mate em regime sustentável, dentro das áreas de reserva legal das propriedades rurais, está prevista no Art. 128-E, da Lei Estadual $\mathrm{n}^{\circ}$ 16.342/14. Em conjunto com o disposto no Art. 124-D da mesma lei, que considera o plantio e adensamento de florestas com espécies nativas como uma atividade de baixo impacto ambiental, há a possibilidade de adensar áreas florestais com o intuito de sua exploração sustentável.

A prática de adensamento de florestas nativas com erva-mate é tradicional na região, ainda que a maior parte da produção ervateira seja proveniente de ervais nativos. Este sistema permite o aproveitamento da propriedade e a percepção de conformidade ambiental e uso sustentável por parte dos agricultores e produtores rurais. Para Marques (207, p. 80):

\footnotetext{
Dessa forma, a erva-mate nativa pode ser um importante estímulo para a conservação ambiental, devido a sua ocorrência no sub-bosque da floresta e de seu significativo valor econômico, o que confere valor monetário para a floresta, [...] contribuindo para a conservação dos remanescentes florestais [...].
}

Segundo Marques (2007), com o propósito de aumentar a rentabilidade, preservar e até mesmo recuperar os fragmentos florestais, há necessidade de algumas ações como incentivar e investir em pesquisas de usos alternativos para ampliação do mercado da erva-mate. Além disso, fazer plantios de múltiplos usos, realizar adensamento dos remanescentes florestais 
nativos com mudas originárias da região, aumentar a qualidade da matéria-prima e manejar os ervais nativos de forma sustentável. Marques (2007, p. 299) sinaliza que:

[...] até o momento não existe um posicionamento claro dos órgãos ambientais em relação [...] ao manejo da erva-mate em paisagens florestais. Sendo necessária, [...] a elaboração de instruções normativas específicas para o manejo da erva-mate em ambientes florestais, que deveriam ser antecedidas de um amplo debate envolvendo todos os setores ligados à atividade ervateira e instituições de pesquisa, extensão e ambientais.

O maior interesse em pesquisas buscando alternativas de usos da erva-mate visando uma produção agroecológica e sem agressões ao meio ambiente, pode aumentar significativamente o aproveitamento sustentável, gerando mais renda aos produtores e dinamizando toda a cadeia produtiva.

Outro PFNM conhecido e que movimenta o mercado informal é o pinhão. Com produção predominante entre os meses de abril e agosto, o pinhão é o produto mais procurado nas Matas de Araucária durante o inverno. Sua exploração é regulamentada, no estado de Santa Catarina pela Lei $n^{\circ} 15.457 / 2011$, que em seu Art $1^{\circ}$ determina a proibição da colheita, transporte e comercialização do pinhão, antes do dia $1^{\circ}$ de abril.

O pinhão e a erva-mate são as principais fontes de extração vegetal da FOM. A coleta anual do pinhão é uma das atividades que, além da renda, promove a valorização dos remanescentes florestais, possibilita uma abordagem harmônica dos seres humanos com a floresta, e pode servir para o estabelecimento de políticas públicas ao desenvolvimento das comunidades e conservação da floresta.

Mesmo com a importância deste produto para a comunidade rural do sul do país, ainda são escassos os dados de mercado e comercialização do pinhão, sendo que os disponíveis ainda são bastante variáveis, o que sugere a demanda por pesquisas sobre o assunto. Neste sentido ações integradas entre instituições de pesquisa e uma das alternativas para atender a demanda por dados; entretanto, um dos maiores desafios ainda é a comoção do meio político e a captação de recursos. Aspectos de conservação da espécie Araucaria angustifolia, como os impactos de tais atividades sobre a regeneração florestal e interferências na dinâmica florestal, são importantes para a segurança ambiental.

Conforme Mazza et al. (2011, p. 24): “[...] pouca valorização e aproveitamento do pinhão, uso restrito do pinhão, esgotamento da capacidade produtiva (pinhas e pinhões), desrama natural de galhos e broca das ponteiras [...]". Outras demandas devem ser mais bem aprofundadas em relação a este produto, como formas de armazenamento, regulação de estoque ao longo do ano, melhor aproveitamento e prolongamento da utilização/conservação da espécie. Além disso, estudos sobre as variedades existentes, aumento do período de produção e outros possíveis usos da araucária, como resinas, por exemplo. Sendo assim, o pinhão pode ser um atributo de especificidade para valorização dos remanescentes florestais e identidade cultural do território.

Ainda tratando dos PFNM, existem os frutos nativos, os quais são um dos produtos da floresta mais apreciados e, atualmente, continuam sendo subaproveitados em diversas regiões. Os seus usos e aplicações no PNC, de um modo geral, estão especialmente relacionados à composição da renda e diversificação da propriedade rural. Assim como a erva-mate, estas espécies florestais apresentam potencial para o enriquecimento de fragmentos, pois ocupam o

DRd - Desenvolvimento Regional em debate (ISSNe 2237-9029) 
sub-bosque da FOM. Nesta formação florestal há destaque para a família Myrtaceae, que possui diferentes espécies, dentre elas, a pitanga (Eugenia uniflora), guabijú (Myrcianthes pungens), guabiroba (Campomanesia xanthocarpa), cerejeira (Eugenia involucrata), araçá (Psidium cattleianum), jabuticaba (Myrciaria trunciflora), uvaia (Eugenia pyriformis) (LORENZI, 2008; 2009a/b), além de outras famílias que englobam as espécies como o araticum (Annona cacans) e o ingá-feijão (Ingá capitata). Outras também são potenciais para o desenvolvimento de PFNM como a guaçatunga (Casearia decandra), e a palmeira jerivá (Syagrus romanzoffiana).

Os frutos nativos possuem características intrínsecas, o mercado local. Estes dispõem de formas de aproveitamentos variados, como o consumo in natura, em polpas, sucos, compotas, geléias, e outros produtos artesanais, os quais são tradicionalmente apreciados pelo paladar local. Conforme Mazza et al. (2011, p. 27):

[...] as ações de pesquisa para cada espécie, mas de uma maneira geral envolvem: localização das populações das espécies, identificação das matrizes e implantação de populações-base; estudo da estrutura populacional em diferentes paisagens; estudos da biologia reprodutiva e propagação; caracterização e avaliação de sistemas de manejo e da produtividade nas diferentes paisagens [...].

Ainda que algumas espécies florestais apresentem potencial de uso para produção de frutos nativos sob diferentes formas de manejo, para estes serem viabilizados, o desafio está além do planejamento da propriedade agrícola e suas formas de aproveitamento. $\mathrm{O}$ direcionamento de políticas de suporte à estruturação da cadeia produtiva e à pesquisa científica são as bases para o uso deste recurso como promotor do desenvolvimento sustentável. No estado de Santa Catarina, o aproveitamento dos frutos nativos está previsto na Lei $\mathrm{n}^{\mathrm{o}} 16.342 / 14$, sob forma de Manejo Florestal Sustentável, devendo atender a critérios ambientais estabelecidos.

Dentre os diversos PFNM destacam-se, nos fragmentos florestais, principalmente em estágios inicial e médio de regeneração, plantas com propriedades farmacológicas. Estas plantas são ricas fontes de substâncias orgânicas de interesse científico e tecnológico. Elas são conhecidas como metabólitos secundários e encontram-se distribuídas por toda a planta. Muitos destes metabólitos desempenham importante papel regulador no desenvolvimento, defesa e na reprodução da planta. Quanto maior a diversidade biológica de uma determinada floresta, maior será a sua diversidade química, podendo-se citar a Mata Atlântica como um dos mais ricos sistemas biológicos do mundo. Conforme Santos (2008, p. 11):

\footnotetext{
Dentre os diferentes produtos de origem vegetal estão os óleos essenciais, misturas de compostos com diversificada estrutura molecular e pertencentes à classe dos terpenos, arilpropanóides e ésteres, podendo apresentar mais de 50 substâncias em sua composição. Eles podem ser usados in natura na formulação de medicamentos, cosméticos e aditivos em alimentos, como também empregados em diferentes setores da indústria química como matéria-prima, sendo transformados em outras substâncias de maior valor agregado.
}

Já, Prochnow (2007, p. 174), diz que: “[...] um dos exemplos é o safrol, originalmente isolado do óleo da Canela-sassafrás (Ocotea odorifera), é utilizado na preparação do piperonal para a indústria de cosméticos e do butóxico de piperonila, para a indústria de defensivos agrícolas". Porém, outras espécies como o caraguatá (Bromelia atiacantha), ervamate, agrimonia (Agrimonia eupatoria), marcela do campo (Achyrocline satureioides), 
aroeira-vermelha (Schinus terebinthifolia), espinheira-santa (Maytenus aquifolia), carqueja (Baccharis trimera), dentre tantas outras, são utilizadas como fontes farmacológicas naturais.

A transformação dos recursos florestais não madeiráveis, tanto alimentícios como fármacos, em produtos processados com alto valor agregado, é possível desde que seja utilizada tecnologia adequada, a fim de reduzir as perdas nutricionais durante seu aproveitamento e garantir sua segurança alimentar. A questão dos fármacos naturais é um pouco mais complexa, mas não menos importante. Talvez, atualmente, seja um dos temas que deve merecer maior atenção dentro do manejo florestal e dos PFNM. No caso das plantas medicinais, o emprego que é dado ao recurso explorado da floresta tem implicações na saúde pública e seu uso deve ser regulamentado pelas entidades sanitárias. Isto limita o potencial de mercado e o grande problema reside na investigação por parte de laboratórios farmacêuticos em pesquisas e estudos de toxicologia e farmacologia, que se fazem necessários para a grande maioria das espécies empregadas na medicina popular.

O desenvolvimento de pesquisas nesta área pode levar, no médio prazo, a um desenvolvimento de técnicas de manejo específicas para as florestas que detém este patrimônio vegetal. $\mathrm{O}$ uso de plantas medicinais para medicamentos fitoterápicos só ganhará espaço se forem conhecidas e se puderem ser reproduzidas integralmente na forma de matéria-prima e em doses quantificáveis para promoverem a cura da doença ou o seu controle. Por isso, é importante o resgate da cultura medicinal com apoio técnico-científico para o desenvolvimento de uma cadeia de produtos naturais oriundos de plantas nativas.

\section{OUTROS USOS SUSTENTÁVEIS ASSOCIADOS À PAISAGEM FLORESTAL}

\section{TURISMO RURAL}

O turismo rural representa um grande desafio e também uma oportunidade de desenvolvimento para muitos municípios de porte pequeno, tipicamente interioranos. Conforme o que está estabelecido pelo Ministério do Turismo, turismo rural é: “[...] conjunto das atividades turísticas desenvolvidas no meio rural, comprometidas com a produção agropecuária, agregando valor a produtos e serviços, resgatando e promovendo o patrimônio cultural e natural da comunidade" (BRASIL, 2008).

Este é um segmento comumente associado à floresta, da qual é enriquecido e muitas vezes criado, por meio da presença de belezas cênicas e paisagens naturais. O potencial de emprego do turismo rural é beneficiado com a possibilidade de estar presente em pequenas propriedades, valorizando aspectos da cultura local.

Neste contexto, o PNC dispõe de paisagens rurais características dos interessados em apreciar a vida no meio rural. $\mathrm{O}$ inverno, as formações de Matas de Araucárias e o consumo de produtos característicos da região, são atrativos para o turismo rural local.

Com vistas a fortalecer a aptidão e adoção da região ao turismo rural, as parcerias entre os diferentes grupos de interesse são essenciais. As interações entre municípios para o estabelecimento de características culturais locais tendem a surtir efeitos significativos. $\mathrm{O}$ 
tema em debate da Indicação Geográfica (IG) da Erva-Mate, para a região do PNC, apresenta potencial em favorecer o desenvolvimento do turismo rural local. $\mathrm{O}$ estabelecimento de projetos intermunicipais como o Roteiro Turístico "Nossa Terra Nossa Gente", entre Bela Vista do Toldo, Canoinhas e Três Barras; O Caminho dos Príncipes, que contempla seis municípios do PNC; dentre outros, são mecanismos que podem ser potencializados turisticamente para este território.

Ainda assim, o turismo rural pode ser explorado na região do PNC, mesmo que não esteja contemplado em projetos específicos. Neste sentido, há exemplos de iniciativas que obtiveram êxito em suas propostas, como o conceito do Agroturismo, aplicado por produtores agrícolas em parceria com o programa Santa Catarina Rural (SC Rural), na região do Planalto Serrano de Lages. Este conceito busca associar o turismo rural à agricultura familiar. Tal atividade está consolidando-se ao longo dos últimos anos por gerar renda e qualidade de vida no meio rural.

\section{PAGAMENTOS POR SERVIÇOS AMBIENTAIS (PSA)}

O sistema de Pagamento por Serviços Ambientais ${ }^{4}$ é uma metodologia que funciona como um mecanismo de mercado nas políticas ambientais. De acordo com o que é apresentado por Fernandes (2009), de um modo geral, este sistema é organizado quando se é possível identificar uma demanda ambiental, como o fornecimento de água adequado, por um conjunto de beneficiários, que se dispõe a remunerar fornecedores, como proprietários rurais, para adotar medidas de preservação ambiental, visando a manutenção e a melhoria da quantidade e qualidade de processos ecológicos.

Atualmente, dentre os conceitos de PSA aceitos e utilizados é:

Uma transação voluntária, na qual, um serviço ambiental bem definido ou um uso da terra que possa assegurar este serviço é comprado por, pelo menos, um comprador de, pelo menos, um provedor, sob a condição de que o provedor garanta a provisão deste serviço (condicionalidade) (WUNDER, 2005, p. 35).

A região do PNC conta atualmente com dois recentes programas de PSA: o programa "Produtor de Água do Rio Vermelho" e o programa do "Corredor Ecológico Timbó". É possível afirmar que estas ações surgiram em função da crescente preocupação ambiental do meio social, dada a alteração da paisagem verificada na região. A evolução das políticas públicas ambientais aliada ao uso dos conceitos de desenvolvimento sustentável, são assim, permeadas e difundidas por meio destes programas, servindo como exemplo à conservação ambiental de outras áreas de interesse público.

\footnotetext{
${ }^{4}$ Os autores Daly e Farley (2004) descrevem os serviços ecossistêmicos ou serviços ambientais como produtos ou processos de funções ecológicas, que, direta ou indiretamente, contribuem para o bem-estar humano, ou têm potencial para fazê-lo no futuro. Eles representam os processos ecológicos e os recursos expressos em termos de bens e serviços que os mesmos fornecem. Conforme o publicado por Guedes e Seehusen (2011), entende-se ainda, pelo termo serviços ambientais (SA), todos os processos gerados pela natureza por meio dos ecossistemas, naturais, ou manejados, quando positivamente, pelo homem, como no caso dos Sistemas Agroflorestais (SAF's), agricultura orgânica, dentre outros.
} 


\section{INICIATIVAS DESENVOLVIDAS NO PNC: o caso do PSA de São Bento do Sul (SC)}

O município de São Bento do Sul, conforme apresentado por Hubel et al. (2011), é rico em nascentes e cursos d'água, estando situado na bordadura da Serra do Mar, abrigando o divisor das águas que fluem em sentido ao Oceano Atlântico e aquelas que correm para a bacia hidrográfica do Rio Negro.

O surgimento do Programa de Pagamento por Serviços Ambientais "Produtor de Água do Rio Vermelho" está relacionado ao cumprimento de um Termo de Ajuste de Conduta (TAC), diante ao Ministério Público, resultante de crime ambiental cometido pela Prefeitura de São Bento do Sul. Na elaboração deste TAC, $\left(n^{\circ} 05 / 2006\right)$, foi priorizada a busca pelo equilíbrio ecológico de áreas que possuem elevado interesse social ao município de São Bento do Sul, como as margens do Rio Vermelho, responsável pelo abastecimento municipal de água. Assim, foi idealizada a criação do programa de Pagamento por Serviços Ambientais em conjunto com um Plano de Recuperação de Áreas Degradadas (PRAD). No ano de 2010, foi aprovada a Lei Municipal no 2.677, que institui a Política Municipal dos Serviços Ambientais e o Programa Municipal de Pagamento por Serviços Ambientais.

A área delimitada ao Programa "Produtor de Água do Rio Vermelho" considerou 49 proprietários, localizados em parte da Bacia Rio Vermelho e inseridas na Área de Preservação Ambiental (APA) do Rio Vermelho/Humbold. Especificamente, serão consideradas as APPs das propriedades, as que preservam a faixa de mata ciliar de até $30 \mathrm{~m}$ do rio, conforme o Programa de Pagamento por Serviços Ambientais "Produtor de Agua do Rio Vermelho" em São Bento do Sul. Para fins do cálculo de pagamento aos beneficiados, foi estabelecida parceria com a Fundação Grupo Boticário de Proteção à Natureza adotando a metodologia de valoração ambiental do Projeto Oásis. A partir desta, são consideradas as áreas, em hectares, de APPs conservadas, ou que estão em recuperação, obtendo sua comprovação verificada em vistorias das práticas desenvolvidas e aplicação de tabela de valoração.

No total foram contempladas dezoito propriedades rurais no Programa "Produtor de Água do Rio Vermelho" ao longo dos anos de 2011 a 2015. Os participantes tiveram adesão espontânea, por meio de vínculo contratual com o Serviço Autônomo Municipal de Água e Esgoto de São Bento do Sul (SAMAE). O valor mínimo recebido por um beneficiado, ao final dos cinco anos, foi de R\$1.922,42, com uma APP de apenas 0,19 ha.

Os resultados socioambientais do Programa "Produtor de Água do Rio Vermelho" foram positivos. Quantitativamente, o valor verificado foi de 44,85 ha de mata ciliar preservada ao longo das margens do Rio Vermelho, e outros 676,25 ha de propriedades rurais que passaram a adotar práticas sustentáveis, na área considerada de elevado interesse ambiental. No total, o valor pago aos dezoito proprietários, no período de 2011 a 2015, somou o montante de R \$58.497,93. Qualitativamente, a recuperação das APPs está relacionada com a conservação das mesmas, e com as ações estabelecidas no PRAD, as quais consistiram especialmente na implantação de cercas nos limites das APPs, plantio de espécies nativas, e na aplicação de técnicas que abrangem o preparo do terreno, com descompactação do solo e o amontoamento de solo, e o uso de práticas de nucleação, por meio de transposição de banco de solo, transposição de chuva de sementes, concentração de material e poleiros artificiais.

Nestes locais, ficou garantida não somente a conservação do meio ambiente, mas, também, ações monitoradas buscando sua recuperação ecológica. As ações estabelecidas 
permitem a expansão da cobertura florestal e maior conexão entre as mesmas, o que é de grande interesse para o fluxo gênico de espécies e manutenção da biodiversidade. Ainda que, uma propriedade detenha pequenas áreas de preservação permanente, se considera viável a adesão ao programa, devido ao estabelecimento de valor mínimo de incentivo, fixado em 122,5 vezes a Unidade Fiscal Municipal (UFM), e a estas áreas apresentarem um baixo custo para a adequação ambiental e aplicação das técnicas de recuperação ambiental. Com a aplicação destes valores de modo planejado, pode ser elevada a eficiência das ações, resultando em uma propriedade regularizada ambientalmente e com uso de conceitos de desenvolvimento sustentável.

\section{INICIATIVAS DESENVOLVIDAS NO PNC: O PROGRAMA DE PSA NO CORREDOR ECOLÓGICO TIMBÓ}

O PSA do Corredor Ecológico Timbó surgiu no ano de 2014, em uma articulação da Fundação de Meio Ambiente do estado de Santa Catarina (FATMA) e da Empresa de Pesquisa Agropecuária e Extensão Rural (EPAGRI) junto ao Programa Santa Catarina Rural (SC Rural), na busca pela conservação dos remanescentes florestais nativos e o desenvolvimento rural. A idealização deste programa de PSA está embasada, dentre diferentes estudos e publicações, na Lei Estadual n ${ }^{\circ} 15.133$, de 19 de janeiro de 2010, conhecida como Política Estadual de Serviços Ambientais (PEPSA).

As propriedades são elencadas de acordo com critérios de prioridade ambiental, como localização estratégica, aliado à presença de remanescentes florestais de mata nativa excedentes às áreas de preservação permanente e reservas legais (FATMA, 2015). Para a valoração ambiental das propriedades foi também adotada e adaptada a metodologia utilizada e desenvolvida pelo Projeto Oásis, da Fundação Grupo Boticário de Proteção à Natureza, parceira desta iniciativa de PSA.

Deste modo, na área do Corredor Ecológico Timbó, três propriedades rurais foram inicialmente contempladas com incentivos econômicos à conservação ambiental. As propriedades estão localizadas no município de Bela Vista do Toldo e somam, em conjunto, um total de nove hectares de floresta nativa conservadas, referente à formação FOM. No ano de 2015, as ações se estenderam também a propriedades inseridas na área do Corredor Ecológico Chapecó, o que apresenta este programa como uma ação socioambiental integrada e planejada.

Para fins de pagamento aos proprietários que aderiram ao programa, foi considerado um valor mínimo de $\mathrm{R} \$ 87,50$ e máximo de $\mathrm{R} \$ 350,00$ por hectare/ano. Além disso, de modo a conduzir o sistema de pagamentos, ficou determinado o limite de até três hectares por propriedade, sendo renováveis por até três anos. A adesão ao programa por parte dos proprietários é espontânea, sendo necessário o preenchimento de manifestação de interesse.

Atualmente, mais de 30 propriedades rurais já estão sob processo de análise somente no Corredor Ecológico Timbó, sendo cinco propriedades no município de Canoinhas, oito em Lebon Régis, dez em Timbó Grande, três em Bela Vista do Toldo, três em Santa Cecília e seis em Irineópolis. A meta do programa é estabelecer a conservação economicamente incentivada em aproximadamente mil hectares (FATMA, 2015). 


\section{CONSIDERAÇÕES FINAIS}

É notório que o tema debatido apresenta em sua gênese as dificuldades e possibilidades com diferentes intensidades. A exploração despreocupada e extremamente intensa, passando pelo ciclo ervateiro e madeireiro no PNC foi intenso e ainda é evidente. Se, de alguma forma, esta afirmação é desanimadora, em oposição devemos acreditar que trabalhar por uma política regional e nacional de desenvolvimento sustentável é extremamente importante a partir dos fragmentos florestais existentes na Mata Atlântica e, neste caso, na Floresta Ombrófila Mista do PNC.

Fica evidente que ações podem ser capazes de mudar o cenário de baixo estímulo, para uma situação de motivação ao uso sustentável dos fragmentos florestais do território em estudo. Para tanto, é necessário direcionar esforços para se criar situações que estimulem a conservação e que não sejam apenas ações defensivas.

Primeiramente, uma recomendação se faz pertinente: a criação de um Plano Regional para Conservação e Recuperação da Mata Atlântica, identificando ameaças e forças para a preservação de remanescentes florestais. Tal ação complementa outros instrumentos de gestão dos municípios, como o Plano Diretor, por exemplo. É de suma importância que, para discussão e elaboração deste plano, exista o envolvimento do poder público municipal, sociedades civis, instituições acadêmicas e também órgãos que trabalhem com pesquisas agropecuárias. Outro apontamento é a adequação ambiental das propriedades rurais. A diversidade de produção juntamente com o respeito ao meio ambiente devem ser as bases para a sustentabilidade econômica e ambiental nas propriedades rurais. Cabe destacar a necessidade de incentivos aos proprietários rurais, a adequação ambiental em relação às áreas de RL e APP, além da promoção para sua recuperação por meio de replantio de árvores, isolamento de áreas, técnicas de restauração florestal e o uso e manejo adequados do solo.

O destaque dado ao manejo florestal para a região está centrado na discussão dos PFNM. Contudo, merecem também destaque estudos de viabilidade sobre manejo florestal. Maiores ações e recomendações são encontradas nas pesquisas realizadas por Petrentchuk (2015), que elencou grande variedade de ações e alternativas a serem desenvolvidas no âmbito de conservação dos remanescentes florestais da FOM, especificamente no município de Canoinhas (SC), mas que pode ser estendido e aplicado aos demais municípios do PNC.

Dentre as classes de PFNM dos fragmentos florestais nativos, a atenção maior merece ser dada a um produto que já possui mais de um século de métodos extrativistas e comerciais, a erva-mate. Atualmente o amplo debate sobre a Indicação Geográfica é destaque na região, visando a criação de um selo que garanta a exclusividade do produto extraído das florestas nativas do município do PNC e sul do Paraná.

Contudo, algumas ações que visem contribuir para o processo de IG e para a manutenção e conservação dos fragmentos florestais foram debatidas no III Workshop sobre Desenvolvimento Regional do Território do Contestado, realizado em agosto de 2014 em Canoinhas (SC), juntamente com o II Seminário de Sistemas de Produção Tradicionais e Agroflorestais no Centro Sul do Paraná e Norte Catarinense.

O processo de destruição e agora de recuperação dos remanescentes florestais evidencia a necessidade de se construir com a população regional uma política de desenvolvimento que considere a importância da FOM para garantir a ocupação social,

DRd - Desenvolvimento Regional em debate (ISSNe 2237-9029) 
produtiva e ambiental de forma viável no PNC. Caso contrário, continua-se presenciando situações de desvalorização dos fragmentos nativos, tendo como consequência a destruição das florestas, com danos irrecuperáveis ao meio ambiente. A desvalorização ou destruição das florestas, poderá representar abrir mão da principal vantagem diferenciadora, que permitiria um padrão sustentável de desenvolvimento regional.

\section{REFERENCIAS}

ALARCON, G. G.; et al. Fragmentação da Floresta com Araucária e Ecossistemas Associados no Corredor Ecológico Chapecó - Santa Catarina. Revistas Biotemas, Florianópolis, n. 24, 2011, p. 27-38, 2011.

ALMEIDA, M. A. Política de desenvolvimento e estruturação do espaço regional da área da Bodoquena em Mato Grosso do Sul. Presidente Prudente: Unesp, 2005. xxiv, 392 f.: il. Tese (Doutorado em Geografia) - Universidade Estadual Paulista. Faculdade de Ciências e Tecnologia. Campus de Presidente Prudente. Presidente Prudente, 2005.

BENNET, E. M.; PETERSON, G. D.; LEVITT, E. A. Looking to the future of ecosystem services. Montreal: Ecosystems, 2005.

BORBA, R. A. V. Planejamento estratégico e desenvolvimento local: uma aplicação da cidade de Londrina. In: COSTA, Armando João da; GRAF, Marcia Elisa Campos. (Org.). Estratégias de desenvolvimento urbano e regional. Curitiba: Juruá, 2011, p. 65.

BRASIL. Ministério do Meio Ambiente (MMA). Brasília, DF, 2011. Disponível em: http://www.ministeriodomeioambiente.or.gov.br Acesso em: 16 jul. 2016.

Lei $\mathrm{n}^{\mathrm{o}}$ 12.651, de 25 de maio de 2012. Institui o Novo Código Florestal Brasileiro.

Diário Oficial da República Federativa do Brasil, Brasília, DF, n. 102, 28 maio 2012, p. 1-

8. Disponível em: <http://pesquisa.in.gov.br/imprensa/jsp/visualiza/

index.jsp?data $=28 / 05 / 2012 \&$ jornal $=1 \&$ pagina $=8 \&$ totalArquivos $=168>$. Acesso em: 06 jul. 2016.

Ministério do Turismo (MTur). Turismo rural. Brasília, DF, 2008. Disponível em:

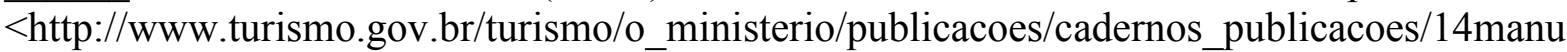
ais.html>. Acesso em: 02 jul. 2016.

BUARQUE, S. C. Construindo o desenvolvimento local sustentável. Rio de Janeiro: Garamond, 2006.

CASTELLA, P. R.; BRITEZ, R. M. A floresta com Araucária no Paraná: conservação e diagnóstico dos remanescentes florestais. Fundação de Pesquisas Florestais do Paraná. Brasília: Ministério do Meio Ambiente, 2004.

CAZELLA, A. A. As Bases Sociopolíticas do Desenvolvimento Territorial: uma análise a partir da experiência francesa. REDES, Santa Cruz do Sul, v. 13, n. 1, p. 05-27, jan./abr.2008. 
Base de serviços rurais estratégicos à promoção do desenvolvimento territorial no Brasil. Raízes, Campina Grande, v. 28, n. 1-2, v. 29, n. 1, p. 132-142, jan. 2009 a jun. 2010.

CHIARAVALLOTI, R. M; PADUA, C. V. Escolhas sustentáveis: discutindo biodiversidade, uso da terra, água e aquecimento global. São Paulo: Urbana, 2011.

CMDMA-Comissão Mundial de Desenvolvimento e Meio Ambiente da América Latina e do Caribe. Nossa própria agenda. New York: BID/PNUD; 1998.

DALLABRIDA, V. R. (Org.). Governança Territorial e Desenvolvimento: Introdução ao tema. In: Governança territorial e desenvolvimento: descentralização políticoadministrativa, estruturas subnacionais de gestão do desenvolvimento e capacidades estatais. Rio de Janeiro: Editora Garamond, 2011. p. 15-38.

Território e desenvolvimento sustentável: Indicação Geográfica da Erva-mate de ervais nativos do Brasil. Informe Gepec, Toledo, v. 16, n. 01, p. 42-59, 2012.

DALY, H. E.; FARLEY, J. Ecological economics: principles and applications. Washington DC, Island Press, 2004.

DINIZ, C. C. Celso Furtado e o desenvolvimento regional. In: SILVA, F. da. (Org.); GRANZIERA, R. G. (Org.). Celso Furtado e a formação econômica do Brasil: edição comemorativa dos 50 anos de publicação: 1959-2009. São Paulo: Atlas, 2009. p. 188-200.

FERNANDES, M. M. Valoração do serviços ambientais da floresta da Mata Atlântica associado à qualidade e quantidade de água na APA do Sana. Tese (Doutorado no curso de Pós-Graduação em Agronomia) - UFRRJ, Rio de Janeiro, 2009.

FUNDAÇÃO DE MEIO AMBIENTE DO ESTADO DE SANTA CATARINA - FATMA. Pagamento por Serviços Ambientais nos Corredores Ecológicos de Santa Catarina Meta do SC Rural. 2015. Disponível em: $<$ http://www.scrural.sc.gov.br/?cat=474>. Acesso em: 26 maio 2016.

GIL, A.C. Como elaborar projetos de pesquisa. 4 ed. São Paulo: Atlas, 2008.

GUERRA, M. P. et al. Exploração, manejo e conservação da araucária (Araucaria angustifolia). In: SIMÕES, L. L.; LINO, C. F. (Ed.). Sustentável Mata Atlântica: a exploração de seus recursos florestais. 1. ed. São Paulo: SENAC, 2002, p. 85-102.

GUERRA, F. G. P. Q. Contribuição dos produtos florestais não madeireiros na geração de renda na Floresta Nacional do Tapajós-Pará. Dissertação (Mestrado no Curso de PósGraduação em Engenharia Florestal) - UFPR, Curitiba, 2008.

HEIDEMANN, F. G.; SALM, J. F. Políticas públicas e desenvolvimento: bases epistemológicas e modelos de análise. 2. ed. Brasília: UnB, 2010. 
HUBEL, M.; MELLO, R.; BOLLMANN, M. Programa de Pagamento por Serviços Ambientais "Produtor de Água do Rio Vermelho" em São Bento do Sul - Santa Catarina. In: XIX Simpósio Brasileiro de Recursos Hídricos. 27 nov a 01 dez. 2011. Maceió Anais do Evento. Maceió, 2011. Disponível em: <http://www.quiriri.com.br/arquivos/Publicacoes/ PGYCQ92N_b266beefc25c05ad76c12c6af10dc5f7.pdf>. Acesso em: 10 jul. 2016

KLEIN, R. M. Mapa fitogeográfico do Estado de Santa Catarina. Itajaí: Herbário Barbosa Rodrigues, 1978.

LORENZI, H. Árvores Brasileiras: Manual de identificação e cultivo de plantas arbóreas do Brasil, 5.ed. Nova Odessa: Instituto Plantarum, 2008. v. 1.

Árvores Brasileiras: Manual de identificação e cultivo de plantas arbóreas do Brasil. 3. ed. Nova Odessa: Instituto Plantarum, 2009a. v. 2.

Árvores Brasileiras: Manual de identificação e cultivo de plantas arbóreas do Brasil, 1.ed. Nova Odessa: Instituto Plantarum, 2009b. v. 3

MACHADO, P. P. Lideranças do Contestado: a formação e a atuação das chefias caboclas (1912-1916). Campinas: Editora da UNICAMP, 2004.

MACIEL, M. L. O milagre italiano: caos, crise e criatividade. Rio de Janeiro: Relume Dumará, 1996.

MARQUES, A. C. Planejamento da paisagem da floresta nacional de Três Barras (Três Barras-SC): Subsídios ao plano de manejo. Dissertação (Mestrado no Programa de Pósgraduação em Geografia) - UFPR, Curitiba, 2007.

MARQUES, A. C. et al.. dos. Florestas Nacionais e o desenvolvimento de pesquisas: o manejo da erva-mate (Ilex paraguariensis St. Hil.) na Flona de Três Barras/ SC.

Biodiversidade Brasileira, Brasília, DF, v. 2, n. 2, p. 4-17, 2012.

MAZZA, C. A. S. et al. Proposta para o Desenvolvimento da Conservação e Uso de Recursos Florestais não Madeireiros na Floresta com Araucária - Programa Conservabio. In: V

Seminário de Áreas Protegidas e Inclusão Social. Manaus: UFAM, 2011.

MEDEIROS, J. de D.; SAVI, M.; BRITO, B. F. A. de. Seleção de áreas para criação de Unidades de Conservação na Floresta Ombrófila Mista. Biotemas, Florianópolis, v.18, n. 2, 2005, 33-50 p.

MILLER, G. T.; SPOOLMAN, S. E. Ecologia e sustentabilidade. São Paulo: Cengage learning, 2012.

PETRENTCHUK, L. W. Possibilidades e desafios do manejo de fragmentos de floresta ombrófila mista como alternativa do desenvolvimento: um estudo com base na realidade socioeconômica ambiental em Canoinhas (SC). Dissertação (Programa de Mestrado em Desenvolvimento Regional) - Universidade do Contestado, Canoinhas, 2015. 
POLLICE, F. O papel da Identidade Territorial nos Processos de Desenvolvimento Local. Espaço e Cultura, Rio de janeiro: UERJ, n. 27, p. 7-23, jan./jun. 2010.

PROCHNOW, M. No jardim das florestas. Rio do Sul: Apremavi, 2007.

O. Parque Nacional das Araucárias e a Estação Ecológica Mata Preta: Unidades de Conservação da Mata Atlântica. Rio do Sul: APREMAVI, 2009.

RAUD, C. Indústria, território e meio ambiente no Brasil: perspectivas da industrialização descentralizada a partir da análise da experiência catarinense. Blumenau: Editora da Furb, 1999.

SACHS, I. Ecodesenvolvimento: crescer sem destruir. São Paulo: Vértice, 1986.

2008.

Desenvolvimento: includente, sustentável, sustentado. Rio de Janeiro: Garamond,

SALVADOR, C.; DA-RÉ, M. Avaliação preliminar dos remanescentes de Floresta de Araucária potenciais para estratégias de conservação no estado de Santa Catarina. Anais do III Congresso Brasileiro de Unidades de Conservação Rede Nacional Pró-Unidades de Conservação. Fortaleza. 2002.

SANTA CATARINA. Lei $\mathbf{n}^{\mathbf{0}} \mathbf{1 5 . 4 5 7}$, de 17 de janeiro de 2011. Regulamenta a Colheita do pinhão. Disponível em: $<\mathrm{http}: / /$ server03.pge.sc.gov.br/LegislacaoEstadual/2011/015457-0110-2011-001.htm>. Acesso em: 12 jun. 2016.

Lei $\mathbf{n}^{\circ}$ 16.342, de 21 de janeiro de 2014. Institui o Código Estadual de Meio Ambiente e estabelece outras providências. Disponível em:

$<$ https://www.legisweb.com.br/legislacao/?id=264890 >. Acesso em: 07 jun. 2016.

SANTOS, F. B. Estudo e caracterização de essências nativas para utilização em sistemas silvipastoris nas pequenas propriedades familiares do Bioma Mata Atlântica. Florianópolis: UFSC, 2008.

SÃO BENTO DO SUL. Lei Municipal no 246, de 14 de Agosto de 1998. Cria a APA- Área de proteção Ambiental do Rio Vermelho, revoga a lei no 696/96 e dá outras providencias.

Disponível em: https://leismunicipais.com.br/a/sc/s/sao-bento-do-sul/leiordinaria/1998/24/246/lei-ordinaria-n-246-1998-cria-a-apa-area-de-protecao-ambiental-dorio-vermelho-revoga-a-lei-n-696-96-e-da-outras-providencias. Acesso em: 07 jun. 2016.

Lei Municipal no 2677, de 24 de Novembro de 2010. Institui a Política municipal do Serviços Ambientais, o Programa Municipal de pagamento por Serviços Ambientais e estabelece formas de controle e Financiamentos desse Programa, e dá outras providencias. Disponível em: $<$ https://leismunicipais.com.br/a/sc/s/sao-bento-do-sul/leiordinaria/2010/267/2677/lei-ordinaria-n-2677-2010-institui-a-politica-municipal-dosservicos-ambientais-o-programa-municipal-de-pagamento-por-servicos-ambientaisestabelece-formas-de-controle-e-financiamento-desse-programa-e-da-outras-providencias2010-11-24.html>. Acesso em: 11 jun. 2016. 
SOS MATA ATLÂNTICA - FUNDAÇÃO SOS MATA ATLÂNTICA e INPE -

INSTITUTO NACIONAL DE PESQUISA ESPACIAIS. Atlas dos Remanescentes

Florestais da Mata Atlântica 2005-2008. Relatório Parcial. São Paulo. 2009.

SOS MATA ATLANTICA- FUNDAÇÃO SOS MATA ATLANTICA e INPE- INSTITUTO NACIONAL DE PESQUISAS ESPACIAIS. Atlas dos remanescentes Florestais da Mata, Atlântica 2005-2008. Relatório Parcial. São Paulo, 2009.

THOMÉ, N. Ciclo da madeira: história de devastação da Floresta da Araucária e do desenvolvimento da indústria madeireira em Caçador e na região do Contestado no século XX. Caçador: Universal, 1995. 212 p.

Trem de ferro: história da ferrovia no Contestado. Florianópolis: Lunardelli, 1983.

TRES, D. R.; REIS, A.; SCHLINDWEIN, S. L. A Construção de Cenários de Relação Homem-Natureza sob uma Perspectiva Sistêmica para o Estudo da Paisagem em Fazendas Produtoras de Madeira no Planalto Norte Catarinense. Campinas: Ambiente e Sociedade, v. XIV, n. 1, jan/jun. 2011. 151-173 p.

VEIGA, J. E. Desenvolvimento sustentável: o desafio do século XXI. Rio de Janeiro: Garamond, 2005. Indicadores de Sustentabilidade. Estudos Avançados, São Paulo, v. 24, n. 68, jan./abr. 2010.

VIBRANS, A. C. et al. Inventario florístico e florestal de Santa Catarina: Floresta Ombrófila Mista. 1. ed. Blumenau: Edifurb, 2013. v. 3.

WUNDER, S. Payments for environmental services: Some nuts and bolts. Revista CIFOR, Indonésia, Occasional Paper, n. 2, p. 1-44, 2005.

Artigo recebido em: 21/06/2016

Artigo aprovado em: 12/07/2016 